\title{
The role of selective venous sampling in patients with non-localized primary hyperparathyroidism
}

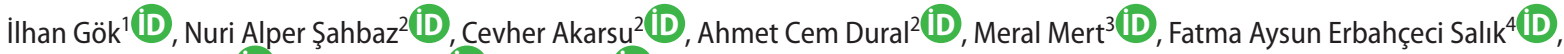

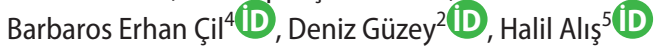 \\ 1 Department of General Surgery, Buyukcekmece Mimar Sinan State Hospital, Istanbul, Turkey \\ ${ }^{2}$ Department of General Surgery, University of Health Sciences, Bakirkoy Dr. Sadi KonukTraining and Research Hospital, Istanbul, Turkey \\ ${ }^{3}$ Department of Endocrinology and Metabolism, University of Health Sciences, Bakirkoy Dr. Sadi Konuk Training and Research Hospital, Istanbul, Turkey \\ ${ }^{4}$ Department of Interventional Radiology, University of Health Sciences, Bakirkoy Dr. Sadi Konuk Training and Research Hospital, Istanbul, Turkey \\ ${ }^{5}$ Department of General Surgery, I.A.Ü. VM Medical Park Florya Hospital, Istanbul, Turkey
}

\begin{abstract}
Objective: The aim of this observational clinical study was to evaluate the success of angiographic selective venous sampling (ASVS) in locating parathyroid adenoma in patients with primary hyperparathyroidism (PHPT), in whom the other imaging modalities have failed, and and to evaluate its possible contribution to the applicability of minimal invasive surgery.

Material and Methods: Fifty-five patients who were admitted to our hospital's General Surgery department between January 2012 and January 2015 for PHPT in whom ultrasound and sestamibi scintigraphy have failed to localize the diseased gland were included to the study. Patients were divided into two groups: those who underwent ASVS and those who did not. The outcomes of patients were reviewed retrospectively.

Results: Among 55 patients, 20 underwent ASVS. ASVS successfully lateralized the diseased gland in 17 (85\%) patients, and minimally invasive parathyroidectomy could be performed in $14(70 \%)$ patients. The cut-off value of parathormon gradient was considered $10 \%$ for lateralization and the accuracy of ASVS in lateralization was $94.1 \%$. In 11 (59\%) patients, the superior-inferior discrimination could be achieved in addition to lateralization.

Conclusion: ASVS has a high sensitivity in locating the diseased gland in patients with PHPT in whom ultrasound and sestamibi scan have failed, and thereby, rendering the performance of minimally invasive surgery possible. Further studies may reveal the role of ASVS in providing useful information about not only lateralization but also the superior-inferior discrimination.
\end{abstract}

Keywords: Primary hyperparathyridism, parathyroid adenoma, selective venous sampling

Cite this article as: Gök I, Şahbaz NA, Akarsu C, Dural AC, Mert M, Erbahçeci SalıkFA, et al. The role of selective venous sampling in patients with non-localized primary hyperparathyroidism. Turk J Surg 2020; 36 (2): 164-171.

Corresponding Author

Ahmet Cem Dural

E-mail: cemdural@hotmail.com

Received: 22.10 .2018

Accepted: 01.05.2019

Available Online Date: 08.06.2020

- Copyright 2020 by Turkish Surgical Society Available online at www.turkjsurg.com

DOI: $10.5578 /$ turkjsurg.4335

\section{INTRODUCTION}

Primary hyperparathyroidism (PHPT) results from the over-secretion of parathormone (PTH) from one or more autonomous parathyroid glands. Once the diagnosis of PHPT is biochemically confirmed, it is determined whether the patient is a candidate for surgery. If a patient is scheduled for PHPT surgery, abnormal parathyroid gland(s) should be localized. Parathyroid glands may be present in an extensive region including the neck and the thorax due to their embryological development.

Preoperative localization of parathyroid glands is crucial as it significantly affects surgical intervention. The most commonly used methods for parathyroid localization include ultrasonography (USG) and Technetium Pertechnetate (Tc 99m) sestamibi scintigraphy. Either method alone can localize abnormal glands with $80 \%$ success rate. Where USG and sestamibi are not successful, computerized tomography (CT) and magnetic resonance imaging (MRI) may be used. Single Photon Emission Computed Tomography (SPECT) and also MRI are particularly useful in identifying glands in the thorax. With recent advances in radiology and nuclear medicine, new modalities such as 4 dimension (4D)-CT or ${ }^{11} \mathrm{C}$ Methionine Positron Emission Tomography (PET) and Choline PET have higher rates of adenoma localization $(1,2)$. But unfortunately, these modalities are available in only a few institutions for now.

In cases where preoperative localization studies fail to define an abnormal gland or if reoperation is required, angiographic selective venous sampling (ASVS) may 
help identify the lateralization of hyperfunctioning parathyroid glands. This method is invasive and should be used for very limited number of patients. An accuracy rate between 33-79\% has been reported in the literature for this method (3).

The conventional surgical approach used in PHPT is bilateral neck exploration (BNE) under general anesthesia (BNE). In experienced hands, success levels reaching 95\% have been reported with BNE (4-6). However, with the developments in preoperative parathyroid localization methods and intraoperative PTH monitorization, minimally invasive parathyroidectomy (MIP) also yields similar or even better results (7).

The primary aim of the present study was to investigate the effectiveness of preoperative ASVS in the localization of adenoma in necessary cases when imaging studies were not useful. The secondary aim of the study was to go further than right-left lateralization and enable superior-inferior localization with ASVS as well. A further aim of the study was to seek an answer to the following question in the literature: "What should be the PTH gradient cut-off value in ASVS?"

\section{MATERIAL and METHODS}

The records of patients who were operated in our surgical department between January 2012 and January 2015 due to hyperparathyroidism were examined retrospectively. A total of 55 patients for whom imaging methods such as USG or sestamibi scintigraphy as well as MRI or CT of the neck and thorax did not lead to localization and who were scheduled for surgery by the Multidisciplinary Endocrine Council were included in the study. Due to inavailability of 4D-CT or PET (neither ${ }^{11} \mathrm{C}$ Methionine nor Choline) and intraoperative PTH monitorization in the institution, ASVS is planned as third line study for localization. A written informed consent for ASVS and for the surgical procedure were received from all patients.

The patients were divided into two groups: The group that received ASVS (study group) and others who did not (control group). Prior to the study, ethics approval was obtained from the local ethics committee (Nr: 2014.13.11, Date: October 10 $\left.{ }^{\text {th }}, 2014\right)$. The study has been performed in accordance with the ethical standards laid down in the 1964 Declaration of Helsinki, and the manuscript was prepared in accordance with STROBE guidelines for case control studies.

\section{Patients}

The first group comprised 20 patients in whom USG and sestamibi scintigraphy and also MRI or CT of the neck and thorax did not reveal localization and who underwent ASVS, while the second group comprised 35 patients in whom USG and sestamibi scintigraphy or other non-invasive imaging studies did not reveal localization. Patients' age, gender, complaints, preoperative calcium, PTH, albumin, phosphorus, vitamin D levels, preoperative USG, sestamibi, other imaging studies, ASVS results, operation type and duration, pre-operative PTH results, parathyroid adenoma localization found in the operation, frozen section results, final pathology results, mass size, and calcium and PTH results on postoperative day 1 , week 3 , month 3 and month 6 were identified. Prior to the operation, consent was obtained from all patients about the details of the invasive procedure they would undergo at the interventional radiology department and the radiation they would be exposed to.

\section{Exclusion Criteria}

Those whose primary focus localization could be found with USG and sestamibi, those with secondary hyperparathyroidism, those with tertiary hyperparathyroidism due to chronic renal disease, and ASVS contraindicated patients (ischemic heart disease in the last 6 months, contrast medium allergy, continuous antithrombotic treatment, etc.) were excluded from the study (Figure 1).

\section{Angiographic Selective Venous Sampling Technique}

All venous sampling was carried out in the angiogram unit with fluoroscopy (Allura Xper FD 20/20; Philips Medical Systems, Best, The Netherlands) under local anesthesia. Venous access was obtained via the right femoral vein. An Introducer (6 F Introducer; Cordis Corporation, Bridgewater, NJ, U.S.A.) was inserted in the right femoral vein with the Seldinger technique. Venous samples were obtained from right and left internal jugular veins, right and left brachiocephalic veins and from the superior vena cava with a vertebral catheter (5 F Vertebral Catheter; Cordis Corporation, Bridgewater, NJ, U.S.A.). Peripheral venous samples were obtained from the right femoral vein. Blood samples were numbered and sent to the biochemistry lab for PTH levels to be examined.

\section{Surgical Technique}

All patients with non-localized PHPT were operated on by experienced endocrine surgeons at the department of general surgery. All operations took place under general anesthesia. Patients in whom localisation was achieved with ASVS underwent MIP, while those in whom localisation could not be achieved with ASVS underwent bilateral neck exploration (BNE).

In BNE, midline was opened in the avascular plane and the thyroid gland was visualized after opening the platysma through standard Kocher incision. Four-gland exploration was done after the ligation of the middle thyroid vein on both sides by retracting the strap muscles laterally and the thyroid gland medially. Suspicious parathyroid gland(s) were excised and sent for frozen section.

In MIP, the skin was incised approximately $1.5 \mathrm{~cm}$ by keeping the sternocleidomastoid muscle lateral to the operative site. The operative site was entered between the strap and sternocleidomastoid muscles. Parathyroidectomy was completed by protecting recurrent nerves and vascular structures, and the material excised was sent for frozen section. 


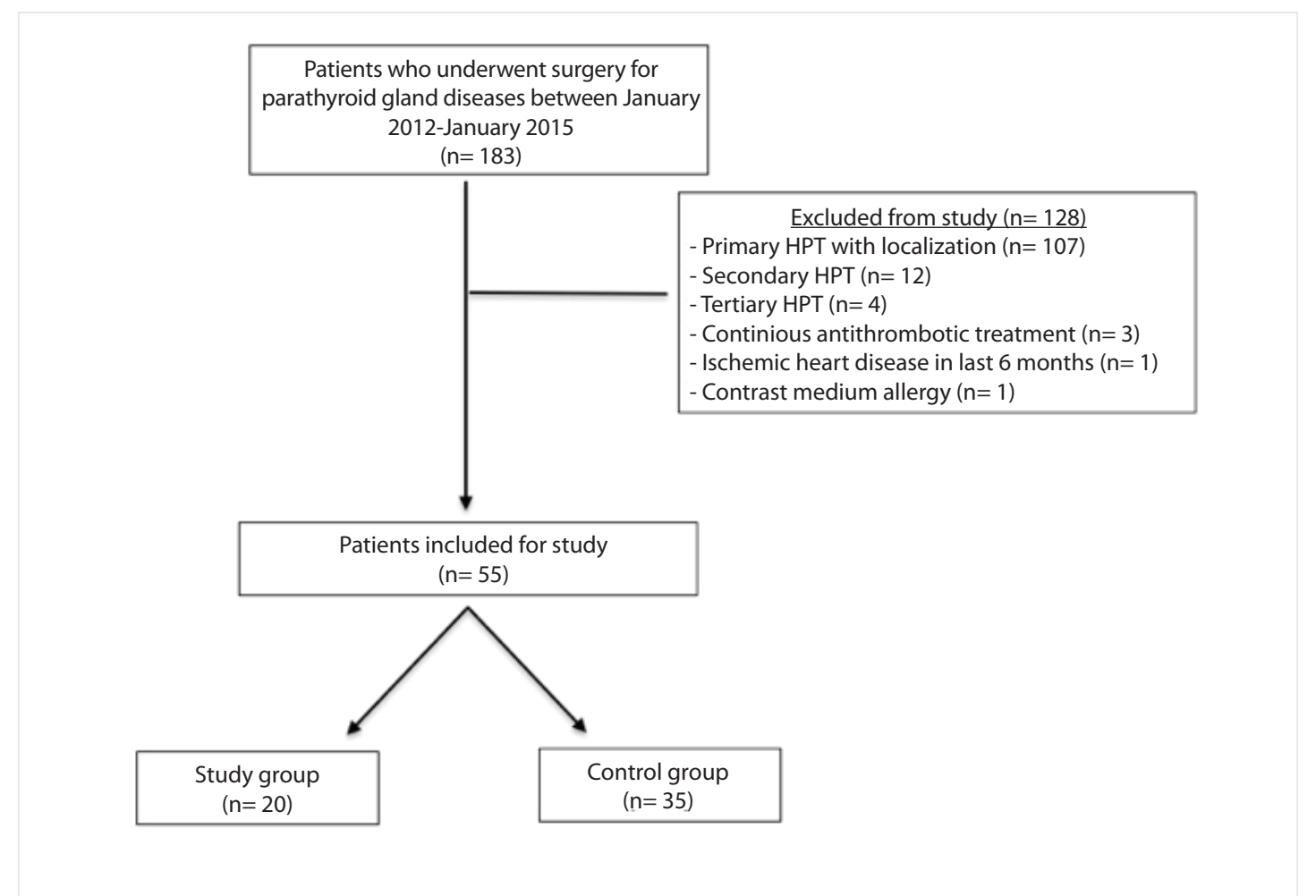

Figure 1. Study flow-chart.

\section{Histopathological Examination}

Specimens from all patients were buried in paraffin blocks and routinely examined after confirming that the material was parathyroid tissue with perioperative frozen section. The specimens were evaluated histopathologically through staining with hematoxylin eosine (H\&E).

\section{Statistical Evaluation}

Data were evaluated via the Statistical Package for the Social Sciences (SPSS 17 for Windows; SPSS Inc, Chicago, IL, U.S.A.). The parametric definitions included mean \pm standard deviation or median (interval). Categorical comparisons utilized chi-square, while comparisons of continuous variables utilized the Student t-test for parametric data and the Mann-Whitney $U$ test for nonparametric data. In the study group, pre and postoperative laboratory values were evaluated for the effectiveness of treatment by using the Wilcoxon test. $p<0.05$ was considered statistically significant.

\section{RESULTS}

Median age was 54 (25-79) in the study group and 57 (35-84) in the control group $(p=0.260)$. Females constituted $90 \%$ of the study group and $85.7 \%$ of the control group ( $p=0.641)$. Duration of surgery in the study group was $45.5 \pm 21.2$ minutes and in the control group $58.4 \pm 28.7$ minutes $(p=0.084)$. Study and control group patients both presented with fatigue, weakness and widespread pain. The two groups did not vary significantly. Likewise, no significant difference existed between the groups regarding reoperative corrected calcium values, preoperative PTH values, preoperative phosphorus values, or preoperative vitamin D levels (Table 1).

In the study group, 14 patients out of 20 (70\%) received MIP. Of the remaining 6 that did not, 4 (20\%) of them were the patients with total thyroidectomy indication owing to concomitant thyroid pathology, and the remaining 2 underwent BNE with Kocher incision as their parathyroid adenoma could not be located.

Intraoperative gamma probe was used in $25 \%$ of the study group and $25.7 \%$ of the control group. No significant difference existed between the two groups regarding the size of the removed parathyroid gland. While preoperative, perioperative and postoperative parathormone levels were examined in the study group, only preoperative and postoperative parathormone values were examined in the control group. Therefore, only preoperative and postoperative parathormone values were compared in order to measure the decline in parathormone levels. This comparison revealed a decrease above 50\% in the parathormone levels in $85 \%$ of the study group $(n=17)$ and $91.5 \%$ of the control group ( $n=32$ ) on postoperative day 1 (Table 2).

Perioperative samples from $75 \%$ of the patients in the study group and $60 \%$ in the control group were sent for frozen. Frozen section was not preferred for patients who did not receive minimal invasive surgery. In 19 (96\%) of the study group patients, pathological results revealed adenoma and in 1 (4\%) parathyroid 
Table 1. Preoperative tests of the study and control groups

\begin{tabular}{|c|c|c|c|}
\hline Parameter & Study group $(n=20)$ & Control group $(n=35)$ & $\mathrm{p}$ \\
\hline \multicolumn{4}{|l|}{ Laboratory $($ mean $\pm S D) *$} \\
\hline Calcium $^{\dagger}(\mathrm{mg} / \mathrm{dL})$ & $11.4 \pm 0.8$ & $11.6 \pm 0.7$ & 0.341 \\
\hline PTH (pg/mL) & $169.7 \pm 30.7$ & $289.6 \pm 57.2$ & 0.132 \\
\hline Phosphorus (mg/dL) & $2.6 \pm 0.5$ & $2.5 \pm 0.7$ & 0.730 \\
\hline Albumin $^{\dagger}(\mathrm{g} / \mathrm{dL})$ & $3.9 \pm 0.5$ & $4.3 \pm 0.4$ & 0.001 \\
\hline 25 hydroxy vitamin D (ng/mL) & $27.0 \pm 2.6$ & $19.9 \pm 11.6$ & 0.051 \\
\hline \multicolumn{4}{|l|}{ Preferred imaging $(n)^{* *}$} \\
\hline USG + sestamibi & 20 & 33 & \multirow[t]{3}{*}{0.348} \\
\hline Additional CT & 4 & 10 & \\
\hline Additional MRI & 13 & 23 & \\
\hline
\end{tabular}

Table 2. Comparison of operation data from the study and control groups

\begin{tabular}{|c|c|c|c|}
\hline Parameter & Study group $(n=20)$ & Control group $(n=35)$ & p \\
\hline Operation type (n, Four-gland/Minimally invasive)* & $6 / 14$ & $15 / 20$ & 0.836 \\
\hline Minimally invasive parathyroidectomy (\%) & 70 & 57.1 & 0.055 \\
\hline Intraoperative gamma probe use (\%) & 25 & 25.7 & 0.953 \\
\hline Size of mass (cm, mean $\pm \mathrm{SD})$ & $1.7 \pm 0.3$ & $1.9 \pm 0.1$ & 0.521 \\
\hline Frozen section use (\%) & 75 & 60 & 0.254 \\
\hline \multicolumn{4}{|l|}{ Drop level from preoperative to postoperative day $1+($ mean \pm SD) } \\
\hline Calcium $(\mathrm{mg} / \mathrm{dL})$ & $2.5 \pm 0.2$ & $2.4 \pm 0.1$ & 0.519 \\
\hline PTH (pg/mL) & $131.6 \pm 35.8$ & $244.4 \pm 58.4$ & 0.179 \\
\hline Mean drop PTH from preoperative to postoperative day 1 (\%) & $76.9 \pm 24.6$ & $87.8 \pm 14.9$ & 0.056 \\
\hline Histopathology (adenoma/hyperplasia) & $19 / 1^{* *}$ & $33 / 2^{* *}$ & 0.986 \\
\hline
\end{tabular}

hyperplasia. The 12-month follow-up of the latter patient showed improved PTH and Ca levels and also improved clinical symptoms. A mismatch was observed between pathological findings and clinical view of this patient. In the control group, pathological findings indicated parathyroid adenoma in 33 (94.2\%) patients and parathyroid hyperplasia in 2 (5.8\%) patients.

Postoperative follow-up of patients included calcium and PTH levels on postoperative day 1, week 3, months 3 and 6 . Postoperative changes in PTH and calcium levels in the study and control groups are shown in Table 3. Calcium values in both groups were in the normal bracket while one patient from each group still had higher than normal PTH values at month 3. No significant difference was found between the two groups regarding the postoperative calcium and parathormone levels (Table 3).
Among the 20 patients in the study group, venous sampling brought accurate parathyroid localization in 17 (85\%) (Table 4). In the remaining 3, localization was not possible with venous sampling. The first one of these 3 patients had previously undergone right lower parathyroid surgery but still had persistent hyperparathyroidism. The failure in this patient was attributed to disrupted vascular pattern due to previous surgery. The second patient had a negative $\mathrm{MIBI}$, and in the USG a lesion appearing to be separate from the thyroid gland on the left inferior posterior, with central vascularization, and giving the impression of a lymph node. Minimally invasive exploration was applied on the left and the tissue was suspected to be parathyroid adenoma. Frozen examination revealed parathyroid tissue and the operation was ended. The third patient had multinodular goiter together with hyperparathyroidism. The exploration revealed widespread thyroid nodules 
Table 3. Comparison of the parameters of 6-month period after the operation in study and control groups

\begin{tabular}{|c|c|c|c|}
\hline Parameter & Study group $(n=20)$ & Control group $(n=35)$ & $\mathrm{p}$ \\
\hline \multicolumn{4}{|c|}{ Postoperative day 1 (mean \pm SD) } \\
\hline Calcium* (mg/dL) & $8.8 \pm 0.2$ & $9.2 \pm 0.1$ & 0.042 \\
\hline PTH $(p g / m L)$ & $38.8 \pm 8.6$ & $44.2 \pm 21.6$ & 0.855 \\
\hline \multicolumn{4}{|c|}{ Postoperative week 3 (mean \pm SD) } \\
\hline Calcium (mg/dL) & $9.4 \pm 1.2$ & $9.1 \pm 1.1$ & 0.342 \\
\hline PTH $(p g / m L)$ & $50.6 \pm 8.8$ & $75.7 \pm 21.1$ & 0.296 \\
\hline \multicolumn{4}{|c|}{ Postoperative month 3 (mean \pm SD) } \\
\hline Calcium (mg/dL) & $9.1 \pm 1.1$ & $11.3 \pm 1.8$ & 0.356 \\
\hline PTH $(p g / m L)$ & $56.8 \pm 13.7$ & $59.5 \pm 8.8$ & 0.874 \\
\hline \multicolumn{4}{|c|}{ Postoperative month 6 (mean \pm SD) } \\
\hline Calcium (mg/dL) & $9.1 \pm 0.5$ & $9.2 \pm 0.3$ & 0.817 \\
\hline PTH $(p g / m L)$ & $12.4 \pm 0.1$ & $44.6 \pm 15.6$ & 0.533 \\
\hline
\end{tabular}

Table 4. Diagnostic success of selective venous sampling in the study group

\begin{tabular}{|l|c|c|}
\hline Selective venous sampling & Diagnosis \% & n/N \\
\hline Direction towards right or left (all cases) & $85 \%$ & $17 / 20^{*}$ \\
\hline Direction towards right or left (cases where left-right difference is > 10\%) & $94.1 \%$ & $16 / 17$ \\
\hline Direction towards lower or upper parathyroid gland on the same side** & $59 \%$ & $10 / 17$ \\
\hline $\begin{array}{l}\text { * Right-left difference was below 10\% in two cases. In one case, double adenoma was identified in right and left upper parathyroids. In the case with left lower pa- } \\
\text { rathyroid adenoma, the difference was 22.7\% in favor of right. } \\
* * \text { Sampling was performed from both jugular veins for upper parathyroid glands, and from both brachyocephalic veins for lower parathyroid glands. }\end{array}$ \\
\hline
\end{tabular}

and four-gland exploration was undertaken. The right lower nodule which was suspected to be intrathyroidal parathyroid was sent for frozen and the suspicion was confirmed. The failure of venous sampling in this patient may have been due to concomitant thyroid nodules and/or the intrathyroidal parathyroid gland. Therefore, localization with venous sampling was not possible in only 1 (5\%) patient with parathyroid adenoma alone.

It was determined that the PTH gradient cut-off value for study group patients who received ASVS could be taken as 10\% because the accuracy rate of lateralization in this case is $94.1 \%$. According to the results of our study, superior-inferior distinction as well as left-right lateralization was achieved in 59\% of the patients (Table 4).

\section{DISCUSSION}

Recent developments in surgical methods, imaging techniques and changing patient expectations have led to the popularity of minimally invasive surgical procedures. As for the treatment of many other diseases, minimally invasive surgical techniques have been defined for parathyroidectomy in order to treat primary hyperparathyroidism. The most important advantages of MIP mentioned in the literature include small incision size, short operation duration and fast recovery. Owing to these advantages, MIP has come to be the most commonly used surgical procedure in PHPT with single gland involvement $(8,9)$.

Minimally invasive parathyroidectomy requires the localization of the hyperfunctioning parathyroid gland. Where localization is not possible, MIP cannot be used. High resolution USG is superior to $M R$ and CT in resolution. Normal size parathyroid glands are often not visible in USG. Various authors have reported USG sensitivity levels ranging between 55-83\% in detecting parathyroid adenoma. USG sensitivity is especially limited, below 29\%, in the mediastinum (10). The capability of USG in identifying parathyroid adenoma is reported by various authors to be between 40-98\% (10).

Sestamibi scintigraphies are used in combination with ultrasound. Where both confirm adenoma, sensitivity reaches 96\% $(11,12)$. Where USG and sestamibi are not successful, MRI is often preferred. It may be particularly effective in suspected cases of ectopic mediastinal gland $(6,13)$.

Bilateral neck exploration is often the preferred procedure in patients of primary hyperparathyrioidism where scintigraphy and USG fail to localize the gland. Experienced hands can locate $98 \%$ of pathological gland(s) with bilateral neck exploration $(6,14)$. However, operation times are much longer than in MIP. In our study, mean operation time for neck exploration and MIP were 73.4 and 
37.5 minutes, respectively. Morbidity rates among patients who undergo neck exploration are also higher than those who undergo MIP. According to the literature, the rate of recurrent nerve injury reported is $2 \%$, also bleeding and hematoma rates are below $0.5 \%$ in BNE $(15,16)$. All these rates are all lower in MIP. Another disadvantage of bilateral neck exploration is the poor cosmetic result that occurs. This negatively affects patients, $70 \%$ of whom are females. The majority of patients therefore prefer MIP solely for cosmetic reasons. To sum up, MIP is clearly more advantageous than bilateral neck exploration. The only issue for MIP; if the adenoma is not found at previously localized area, BNE is required according to the current consensus guidelines (6).

There is no consensus in the literature about the optimal approach to be preferred in cases where sestamibi, USG and MRI are inadequate in localizing the adenoma. Conventional imaging methods may fail to localize parathyroid glands when hyperactive parathyroid glands are small, there are multiple hyperfunctioning glands, or additional thyroid pathologies are present (17).

The goal in parathyroid surgery is to remove the hyperfunctioning gland at first trial. If the glands cannot be localized at this time, future operations have lower success chance and higher complication rates. In our study, two patients required reoperation. The first patient had retrosternal adenoma in the superior mediastinum which could not be located through neck exploration. In this patient, hypercalcemia did not improve despite undergoing 3.5 parathyroidectomy with total thyroidectomy in the first operation. Although preoperative scintigraphy, USG and MRI of the neck could not locate the adenoma, postoperative MRI of the thorax showed a retrosternal hyperfunctioning gland which was consequently removed in a second operation. In the second patient, ASVS showed findings of a right lower parathyroid adenoma, which was excised through MIP. Even though pathology results were compliant with parathyroid adenoma, the patient's persistent hypercalcemia continued. In this patient's second operation, a second right lower parathyroid adenoma was identified, excised and sent for frozen. This patient was diagnosed as having double adenoma.

It is obvious that new methods are available for localizing parathyroid adenoma. However, these new methods such as 4D-CT or PET with 11C Methionine or Choline are not widely used yet in many countries such as our country. Where conventional methods are not successful, ASVS may still help localize parathyroid adenoma in the neck (6).

Angiographic selective venous sampling has generally been used to localize parathyroid glands postoperatively that can not be localized through neck exploration. However, it is harder to interpret ASVS results following neck operations that disrupt vascular drainage. In our study, ASVS was performed on a patient who was previously operated on due to thyroid cancer and subsequently developed unlocalized primary hyperparathyroidism. In this patient, ASVS helped accurate localization and MIS was used to excise the parathyroid adenoma. Even though ASVS has lower success rates among patients with previous neck surgery, it affected the choice of surgical strategy for this particular patient and ensured that the operation and complication risks were smaller.

Complications such as contrast medium oversensitivity reaction (renal deficiency, anaphylactic reaction, etc.), bleeding, infection, pseudoaneurysm, and arteriovenous fistulae are very rare after ASVS, and risks are minor and less frequent compared to bilateral neck exploration. In our study, we did not witness any complications due to ASVS.

ASVS is not an initial method, but a minimally invasive technique to be preferred when non-invasive investigations fail to locate (6). It is a diagnostic method that should definitely be considered in the identification of unlocalized adenoma owing to its potential to prevent repeated surgical operations and make surgery minimally invasive, even though it is an invasive technique itself. In this study, parathyroid adenoma could not be clearly localized with scintigraphy and USG in any of the 55 patients. The 20 patients in the study group received ASVS for localization. The technique was successful in 17 (85\%) patients and 14 of them underwent MIS. Venous sampling was not adequate for localization in the remaining 3 patients. The first patient had undergone right lower parathyroid surgery previously, but had persistent hyperparathyrodism. The failure in this patient was probably due to vascular pattern disruption after previous surgery. The second patient had a lesion with negative MIBI which gave the impression of a lymph node in USG. The lesion, which was defined as a lymph node in exploration, was later identified as parathyroid adenoma. The third patient had concomitant multinodular goitre with hyperparathyroidism, and this patient's hyperfunctioning parathyroid gland was intrathyroidal. The failure of venous sampling in this patient may have been due to accompanying thyroid nodules and/or the intrathyroidal parathyroid gland. ASVS did not lead to localization in only 1 (5\%) patient with a single parathyroid adenoma. Our study aimed to achieve localization with ASVS prior to initial surgery in patients whose parathyroid adenoma could not be localized preoperatively. ASVS has been used by numerous authors in the literature prior to the perioperative removal of adenoma, and later when identifying whether or not quick PTH levels drop in the samples from the jugular vein. Such uses of ASVS aim to evaluate the sufficiency of perioperative parathyroidectomy rather than to achieve parathyroid localization. However, our study used ASVS alone as a localization technique in the preoperative stage. Barczynski et al. report venous sampling to increase the chance of localizing parathyroid adenoma with USG from 33.3\% to 65.4\% in patients with negative sestamibi (18). When parathyroid adenoma gets localized with ASVS and a re-examination with preoperative USG confirms the adenoma, the localization may be marked for a more accurate and appropriate incision.

Perioperative frozen section was preferred for $75 \%$ of the study group patients and $60 \%$ of the control group patients. Frozen 
section was not preferred for patients who did not undergo MIP. Pathology results in the study group revealed adenoma in 19 (96\%) and parathyroid hyperplasia in 1 (5\%). In the control group, pathology results revealed parathyroid adenoma in 33 (94.3\%) and parathyroid hyperplasia in 2 (5.7\%). While the literature reports that parathyroid hyperplasia plays a role in the etiology of approximately $15-20 \%$ of primary hyperparathyroidism patients, the rate of parathyroid hyperplasia was smaller in our study. The two groups did not vary significantly regarding the size of parathyroid glands removed $(p=0.521)$. As no significant difference was found in parathyroid gland size where ASVS achieved localization, no relationship could be found between SVS and parathyroid size.

No consensus has been reached on a single technical method in previous ASVS studies and, more importantly, no cut-off values have been reported. In one of the rare studies on this topic, Maceri et al. have reported $100 \%$ success rate in jugular venous sampling when PTH gradient $>200 \%$, and $88 \%$ success rate when PTH gradient was between 20-200\% (19).

Another important goal of our study was to determine cut-off values for localization in ASVS. Out of the 17 patients in this study in whom localization was successful, 16 (94.1\%) had PTH gradient $>10 \%$. More comprehensive studies are needed on this topic. In our study, we accepted that the cut-off value needed to be $10 \%$.

Angiographic selective venous sampling has most commonly been used in the literature for either right or left lateralization. However, considering the principles and concept of minimally invasive focus surgery, merely right-left lateralization is not adequate. Another goal of our study was to test the effectiveness of ASVS in determining superior-inferior localization as well as rightleft lateralization. We obtained accurate superior-inferior localization in 10 (59\%) of the 17 patients in whom accurate lateralization could be achieved. In this study, we attempted to make inferior and superior distinction as well as right and left localization by increasing the number of ASVS samples. Lower and upper parathyroid adenoma distinction was successful in 10 (62.5\%) of the 16 patients whose ASVS localization was also successful. We are of the opinion that these success rates will increase with more selective vascular cannulation thanks to the advances in angiography. Without a doubt, precise localization will enable minimally invasive surgery in the true meaning of the word.

Small number of cases is the major limitation of our study. However, the number of these patients represents the minority of the patients with PHPT who had surgery between 2012 and 2015 in our institution. Another limitation is the lack of radiologist who is focused on endocrine ultrasound, which might also be a factor to increase the rate of accurate diagnosis for PHPT. Our institution could be considered as a large volume center for parathyroid surgery based on the case numbers per year; however, the lack of modern diagnostic modalities such as 4D-CT or PET-CT (choline or $11 \mathrm{C}$ methionine) and intraoperative PTH assay kits during the period of this study is the third limitation. Despite all these limita- tions, this study emphasizes the role of ASVS which is still a third line diagnostic tool in latest international guidelines.

\section{CONCLUSION}

ASVS is a limited but reliable method for localizing previously unlocalized parathyroid adenoma. It should be used as third line localization study after US/sestamibi and CT/MRI. It eliminates the need for neck exploration and enables patients to undergo MIP, which has fewer complications and similar success rates. In addition to right-left lateralization, ASVS can also reveal superior-inferior localization. Future randomized controlled trials are needed into this topic.

Ethics Committee Approval: Prior to the study, ethics approval was obtained from the local ethics committee (Nr: 2014.13.11, Date: October $10^{\text {th }}$, 2014).

Informed Consent: Informed consent form was obtained from all patients.

Peer-review: Externally peer-reviewed.

Author Contributions: Concept - C.A., I.G., H.A.; Design - C.A., M.M., F.A.E.S.; Supervision - H.A., M.M., B.E.Ç., D.G.; Data Collection and/or Processing - I.G., N.A.Ş., F.A.E.S., D.G.; Analysis and Interpretation - A.C.D., C.A., M.M., N.A.Ş.; Literature Review - D.G., I.G., B.E.Ç.; Writing Manuscript - I.G., A.C.D., N.A.Ş., F.A.E.S.; Critical Reviews - H.A., A.C.D., B.E.Ç.

Conflict of Interest: The authors have no conflicts of interest.

Financial Disclosure: Financial support was provided by departmental sources.

\section{REFERENCES}

1. Tian Y, Tanny ST, Einsiedel P, Lichtenstein M, Stella DL, Phal PM, et al. Four-dimensional computed tomography: clinical impact for patients with primary hyperparathyroidism. Ann Surg Oncol 2018; 25(1): 117-21. [CrossRef]

2. Piccardo A, Trimboli P, Rutigliani M, Puntoni M, Foppiani L, Bacigalupo $L$, et al. Additional value of integrated $18 \mathrm{~F}$-choline PET/4D contrastenhanced $C T$ in the localization of hyperfunctioning parathyroid glands and correlation with molecular profile. Eur J Nucl Med Mol Imaging 2018 Sep 15. doi: 10.1007/s00259-018-4147-4. [CrossRef]

3. Sneider MS, Solorzano CC, Lew Jl. Primary hyperaldosteronism. In: Morita SY, Dackiw APB, Zeiger MA, editors. Endocrine Surgery. New York-Toronto: McGraw-Hill Medical Companies; 2010. pp. 126-39. [CrossRef]

4. Proye C, Carnaille B, Quievereux JL, Combemale F, Oudar J, LecompteHoucke M. Late outcome of 304 consecutive patients with multiple gland enlargement in primary hyperparathyroidism treated by conservative surgery. World J Surg 1998; 22: 526-9. [CrossRef]

5. Siperstein A, Berber E, Barbosa GF, Tsinberg M, Greene AB, Mitchell J, et al. Predicting the success of limited exploration for primary hyperparathyroidism using ultrasound, sestamibi and intraoperative parathyroid hormone: analysis of 1158 cases. Ann Surg 2008; 248(3): 420-8. [CrossRef]

6. Wilhelm SM, Wang TS, Ruan DT, Lee JA, Asa SL, Duh QY, et al. The American association of endocrine surgeons guidelines for definitive management of primary hyperparathyroidism. JAMA Surg 2016; 151(10): 959-68. [CrossRef] 
7. Lal G, Clark OH. Thyroid, parathyroid and adrenal. In: Brunicardi FC, editor. Schwartz's Principles of Surgery. $10^{\text {th }}$ ed. New York-Toronto: McGraw-Hill Education; 2015. pp. 1521-97. [CrossRef]

8. Marx SJ. Hyperparathyroid and hypoparathyroid disorders. N Engl J Med 2000; 343: 1863-75. [CrossRef]

9. Reidel MA, Schilling T, Graf S, Hinz U, Nawroth P, Büchler MW, et al. Localization of hyperfunctioning parathyroid glands by selective venous sampling in reoperation for primary or secondary hyperparathyroidism. Surgery 2006; 140(6): 907-13. [CrossRef]

10. Hopkins CR, Reading CC. Thyroid and parathyroid imaging. Semin Ultrasound CTMR 1995; 16(4): 279-95. [CrossRef]

11. Palestro CJ, Tomas MB, Tronco GG. Radionuclide imaging of the parathyroid glands. Sem Nucl Med 2005; 35: 266-76. [CrossRef]

12. Moore PRB, Lebowitz E, Grene MW, Atkins HL, Ansari AN. Thallium-201 for medical use II: Biologic Behavior. J Nuc Med 1975; 16(2): 156-60. [CrossRef]

13. Ugur O, Bozkurt MF, Rubello D. Nuclear medicine techniques for radioguided surgery of hyperparathyroidism. Minerva Endocrinol 2008; 33(2): 95-104. [CrossRef]

14. Özarmağan S, Erbil Y, Ünalp HR, editors. Tiroid ve Paratiroid Cerrahisi Atlası. Istanbul: Türk Cerrahi Derneği- Ekspres Basımevi; 2010. [CrossRef]
15. lacobone M, Viel G, Zanella S, Bottussi M, Frego M, Favia G. The usefulness of preoperative ultrasonographic identification of nonrecurrent inferior laryngeal nerve in neck surgery. Langenbecks Arch Surg 2008; 393(5): 633-8. [CrossRef]

16. Stavrakis Al, Ituarte PH, Ko CY, Yeh MW. Surgeon volume as a predictor of outcomes in inpatient and outpatient endocrine surgery. Surgery 2007; 142(6): 887-99. [CrossRef]

17. Wakamatsu H, Noguchi S, Yamashite H, Yamashite H, Tamura S, Jinnouchi S, et al. Technetium-99 tetrofosmin for parathyroid scintigraphy: a direct comparison with $99 \mathrm{mTC}-\mathrm{MIBI}, 201 \mathrm{TI}, \mathrm{MRI}$ and US. Eur J Nuc Med 2001; 28: 1817-27. [CrossRef]

18. Barczynski M, Konturek A, Hubalewska-Dydejczyk A, Cichon S, Nowak W. Utility of intraoperative bilateral internal jugular venous sampling with rapid parathyroid hormone testing in guiding patients with a negative sestamibi scan for minimally invasive parathyroidectomy: a randomized controlled trial. Langenbecks Arch Surg 2009; 394: 82735. [CrossRef]

19. Maceri DR, Kokot N, Green K, Montgomery M, Sharifi J. Split central venous sampling of parathyroid hormone: an adjunct to surgical exploration. Head Neck 2011; 33: 1715-8. [CrossRef]

\section{ORIJINAL ÇALIŞMA-ÖZET}

Turk J Surg 2020; 36 (2): 164-171

\section{Yeri belirlenemeyen primer hiperparatiroidi hastalarında selektif venöz örneklemenin yeri}

\section{İlhan Gök ${ }^{1}$, Nuri Alper Şahbaz ${ }^{2}$, Cevher Akarsu² ${ }^{2}$ Ahmet Cem Dural ${ }^{2}$, Meral Mert ${ }^{3}$, Fatma Aysun Erbahçeci Salık ${ }^{4}$, Barbaros Erhan Çil ${ }^{4}$,} Deniz Güzey², Halil Alış

1 Büyükçekmece Mimar Sinan Devlet Hastanesi, Genel Cerrahi Bölümü, İstanbul, Türkiye

${ }^{2}$ Sağlık Bilimleri Üniversitesi Bakırköy Dr. Sadi Konuk Eğitim ve Araşıırma Hastanesi, Genel Cerrahi Bölümü, İstanbul, Türkiye

${ }^{3}$ Sağlık Bilimleri Üniversitesi Bakırköy Dr. Sadi Konuk Eğitim ve Araştırma Hastanesi, Endokrinoloji ve Metabolizma Hastalıkları Bölümü, İstanbul, Türkiye

${ }^{4}$ Sağlık Bilimleri Üniversitesi Bakırköy Dr. Sadi Konuk Eğitim ve Araştırma Hastanesi, Girişimsel Radyoloji Bölümü, İstanbul, Türkiye

${ }^{5}$ I.A.Ü. VM Medical Park Florya Hastanesi, Genel Cerrahi Bölümü, İstanbul, Türkiye

\section{ÖZET}

Giriş ve Amaç: Gözlemsel klinik çalışmamızın amacı primer hiperparatiroidi (PHPT)'li hastalarda diğer görüntüleme yöntemleri ile lokalize edilemeyen paratiroid adenomunun saptanmasında anjiyografik selektif venöz örnekleme (ASVÖ) tekniğinin lokalizasyon başarısını tespit etmek ve minimal invaziv cerrahi uygulanabilirliğine katkısını değerlendirmektir.

Gereç ve Yöntem: Hastanemiz Genel Cerrahi Kliniğine Ocak 2012-Ocak 2015 tarihleri arasında başvuran, ultrasonografi veya sestamibi sintigrafi ile yeri lokalize edilemeyen 55 hasta çalışmaya dahil edildi. Hastalar ASVÖ yapılanlar ve yapılmayanlar olarak ikiye ayrıldı. Hastaların sonuçları retrospektif olarak incelendi.

Bulgular: Elli beş hastanın 20'si ASVÖ grubunda yer almıştır. Bu hastaların 17 (\%85)'sinde venöz örnekleme ile doğru paratiroid lokalizasyonu yapılabilmiş ve bu hastaların 14 (\%70)'üne minimal invaziv paratiroidektomi uygulanmıştır. Lateralizasyon için parathormon gradiyent eşik değeri $\% 10$ olarak kabul edilmiş ve hastalarda lateralizasyonun doğruluk oranı $\% 94,1$ olarak bulunmuştur. Hastaların \%59'unda sağ sol lateralizasyonuna ek olarak süperior-inferior ayııımı da başarılmıştır.

Sonuç: ASVÖ görüntüleme yöntemleri ile lokalize edilemeyen PHPT'li hastalarda duyarlılığı yüksek bir yöntemdir ve bu sayede hastalara minimal invaziv cerrahi yapılabilir. Daha geniş çalışmalar sayesinde sadece sağ-sol lokalizasyonu dışında süperior-inferior lokalizasyonu hakkında da bilgi verebilecek bir yöntemdir.

Anahtar Kelimeler: Primer hiperparatiroidizm, paratiroid adenom, selektif venöz örnekleme

Doi: 10.5578/turkjsurg.4335 